\title{
Identification of Methicillin Resistant Staphylococcus intermedius and Staphylococcus aureus in Dogs with Pyoderma
}

\author{
M. A. Kshama ${ }^{1}$, S. Yathiraj ${ }^{1}$, Srikrishna Isloor ${ }^{2}$, S. Sundaresh ${ }^{2}$ and B. H. Veeresh ${ }^{2}$ \\ ${ }^{1}$ Department of VCC, ${ }^{2}$ Department of Veterinary Microbiology, Blore, Veterinary College, \\ Bangalore Karnataka-560024 (part of PhD thesis) \\ *Corresponding author
}

\section{A B S T R A C T}

Clinical cases presented to Veterinary College Hospital, Bangalore, Karnataka were used as subjects for the study. Samples were collected from lesions of dogs showing clinical signs typical of pyoderma and were subjected to bacterial isolation and culture with

\section{Keywords}

S. intermedius, $S$ aureus, Pyoderma, mecA, Methicillin, Resistance

\section{Article Info}

Accepted:

17 August 2020 Available Online: 10 September 2020 mannitol salt agar, coagulase and catalase testing and biochemical characterization for species differentiation as per standard procedures. Of the 91 samples examined, 88 were coagulase positive staphylococci, which following biochemical characterization were classified as S.aureus (16 isolates) and $S$ intermedius (72 isolates). These were further subjected to sensitivity testing for Methicillin / Oxacillin by disc diffusion as per standard procedures. Fourteen of the 88 isolates were found to be methicillin resistant of which 5 isolates were $S$ aureus and 9 were $S$ intermedius. Six of the methicillin resistant isolates (Four $S$ intermedius and two $S$ aureus as per biochemical characterization) were further subjected to DNA extraction and PCR targeting the mecA gene specific for methicillin resistance. Four of the 6 isolates ( $3 S$ intermedius and one $S$ aureus) yielded $304 \mathrm{bp}$ corresponding to mecA gene, one of the primary genes responsible for methicillin resistance The variation between the results observed by disc diffusion and PCR in this study may be due to the fact that there are additional genetic material responsible for methicillin resistance including genes encoding production of Panton Valentine Leucocidin (PVL) Thus the negative results of 2 of the isolates for mecA gene in the present study could be attributed to either overestimation of methicillin resistance by disc diffusion or it could be due to some other gene mediating resistance.

\section{Introduction}

Dermatological disorders are one of the primary disorders encountered in small animal practice. Of these, pyoderma is one of the most common dermatological disorders diagnosed. It is also one of the most frustrating problems to cope with both for the pet owner as well as the clinician primarily because of the long duration of therapy required, frequent recurrence and also due to the fact that every major or minor dermatological disorder would invariably result in secondary pyoderma. Though several causes have been implicated as precipitating factors, it is essentially a bacterial infection of 
the skin. Until very recently $S$ aureus was believed to be the primary pathogen responsible for pyoderma. However later on i.e. in the 80 's it was found that another coagulase positive Staphylococci, $S$ intermedius was the main etiological agent implicated in pyoderma (Ihrke, 1983; Hoskin et al., 1985; Kunkle, 1987; DeBoer, 1995; Mason, 1997; Craig, 2003). More recently, however $S$ intemedius has been reclassified and it now belongs to a group of organisms referred to as SIG comprising of $S$ intermedius, $\mathrm{S}$ pseudintermedius and $S$ delphini. Of these species, it is now known that $S$ pseudintermedius is the organism responsible for causing pyoderma in dogs (Fitzgerald, 2009; Zakour et al., 2012) and it was in 2005 that it was first identified as the primary etiological agent for canine pyoderma ((Devriese et al., 2005) However, it is often reported as $S$ intermedius as it cannot be differentiated from $S$ intermedius by any of the routine biochemical diagnostic tests available for differentiating different species of staphylococci (Devriese et al., 2005).

The increased incidence of staphylococcal infections in humans and the indiscriminate use of antibiotics has now resulted in the emergence of Methicillin Resistant Staphylococci (MRS). Methicillin Resistant Staphylococcus aureus (MRSA) is being reported worldwide over the last several years in humans as well as animals. Of late, however Methicillin Resistant Staphylococcus intermedius (MRSI) and Methicillin Resistant Staphylococcus pseudintermedius (MRSP) are also being reported (Frank and Loeffler, 2012). S intermedius was normally believed to be pathogenic only in dogs. However now there are several reports wherein they are implicated in human infections. Thus due to the close association between human beings and dogs as pets presence of Methicillin Resistant Staphylococcus intermedius could have far reaching zoonotic implications, making early detection and diagnosis of paramount importance. The present study was a part of a larger study on pyoderma in dogs.

\section{Materials and Methods}

Cases of dermatological disorders were selected non randomly for the study based on detailed history, clinical examination and skin scraping examination. Lesions such as pustules, masses, nodules were first cleaned with sterile cotton and punctured using $2.5 \mathrm{ml}$ sterile dispovan syringes with 21 Guage needles. Materials were then collected aseptically from these lesions by aspiration of the contents. The material so collected using sterile swabs from lesions was inoculated into Brain Heart Infusion broth and incubated at $37^{\circ} \mathrm{C}$ for $12-24 \mathrm{hrs}$. A loopful of the inoculum was then streaked on to pre-prepared Mannitol Salt Agar petriplates and incubated for $24 \mathrm{hrs}$ at $37^{\circ} \mathrm{C}$ and the morphology examined as per the standard procedure described by Cruickshank et al., (1975). Following the study of morphology and plate reading, the isolates identified as staphylococci were subjected to subinoculation onto Brain Heart Infusion agar petriplates and incubated at $37^{\circ} \mathrm{C}$ for $12-24$ hrs. They were further subjected to Grams staining, followed by catalase testing and coagulase testing (tube coagulase test) as per the procedure described by Elmer et al., (1988) and further subjected to biochemical characterization to differentiate the different species using the Histaph Kit (Hi Media, India)

\section{Methicillin sensitivity / resistance testing and detection of MRSA and MRSI}

Antibiotic sensitivity testing for methicillin was carried out using Methicillin (MET $5 \mathrm{mg}$ ) as well as Oxacillin (OX $1 \mathrm{mcg}$ ) discs by disc diffusion method as per the procedure described by Bauer et al., (1966). The 
materials from isolates which were positive for staphylococci were streaked uniformly onto sterile petriplates containing Mueller Hinton Agar and antibiotic discs placed on them and examined after incubation as per the procedure described. The zone of inhibition was then measured using the standard chart provided with the discs and expressed in millimetres. Sensitivity / resistance was assessed based on comparison with the standard chart provided with the discs.

A few of the isolates (6) found resistant to methicillin by disc diffusion method were further subjected to DNA extraction as per the standard protocol prescribed by the manufacturer using the kit procured from Real Genomics (Hi Yield Genomic DNA mini kit) and PCR for detection of mecA gene responsible for methicillin resistance

PCR was carried out using a programmable master cycler (Eppendorf, Germany) as per the procedure described. The reaction mixture of $25 \mathrm{ul}$ (using 10X Taq buffer, Taq polymerase, dNTPs, Primers, Template and Nuclease Free Water) was prepared in a step wise manner as per procedure in $0.2 \mathrm{ml}$ thin walled PCR tubes placed in mini cooler. After mixing the contents, the tubes were centrifuged and fitted with caps and placed firmly inside the thermal cycler and the thermal cycler conditions were set as detailed below.

1. Initial denaturation at $94^{\circ} \mathrm{C}$ for $5 \mathrm{~min}$ followed by

2. Denaturation at $94^{\circ} \mathrm{C}$ for $30 \mathrm{sec}$

3. Annealing at $50^{\circ} \mathrm{C}$ for $30 \mathrm{sec}$

4. Extension at $72^{\circ} \mathrm{C}$ for $1 \mathrm{~min}$

5. Final extension at $72^{\circ} \mathrm{C}$ for $10 \mathrm{~min}$

6. Hold at $4^{\circ} \mathrm{C}$

The steps 2, 3, 4 were repeated (programmed) for 30 cycles. After completion of PCR, $3 \mathrm{ul}$ of the amplified products along with $100 \mathrm{bp}$
DNA ladders added with $6 \mathrm{X}$ gel loading dye were subjected to electrophoresis on $2 \%$ agarose gel (prepared using TAE buffer, agarose and Ethydium Bromide).One positive control and one negative control were used with the test samples. The primers (Staph mecA gene) (F-T G G C T A T C G T G T C A C A A T C G and R-C T G G A A C T T G T T G A G C A G A G) which were designed at the Department of Microbiology,Veterinary College, Bangalore for the Indo-American project on "Rational development of an effective vaccine for prevention of staphylococcal mastitis in bovines" were used for the study (Sundareshan, 2012). The images were captured using Gel Documentation system.

\section{Results and Discussion}

\section{Identification of Staphylococcal organisms responsible for causing pyoderma in dogs}

All 91 samples subjected to bacterial culture showed growth on MSA (Fig. 1\& 2). On coagulase testing 88 of the isolates were found to be coagulase positive (Fig. 3) and 3 were coagulase negative (Table 1). All the 88 isolates were catalase positive. Grams staining revealed the presence of Gram positive cocci (Fig. 4 and 5). The samples included cases of primary pyoderma as well as pyoderma secondary to other dermatological disorders such as demodicosis, atopy and flea allergy dermatitis. After observing the colony morphology, and subculturing, the isolates were further classified species-wise based on the results of biochemical tests using a commercial biochemical assay Kit (Fig 6). Seventy two $(81.81 \%)$ of the 88 coagulase positive isolates were found to be $S$. intermedius and Sixteen $(18.18 \%)$ of the isolates were S.aureus.

Generally the bacteria associated with pyoderma includes $S$. aureus, S. intermedius / 
S pseudintermedius, S. schleiferi, Proteus spp and $E$ coli. However reports from several workers including Ihrke (1983), Berg et al.(1984), Hoskin et al., (1985), Kunkle (1987) have indicated that Staphylococci and especially $S$. intermedius is the primary pathogen in pyoderma and the others are usually secondary invaders. In view of this, emphasis was laid on identifying different species of staphylococci causing pyoderma in the cases presented at the Veterinary College Hospital, Bangalore, Karnataka

The occurrence of $81.82 \%$ of S. intermedius and $18.18 \%$ S. aureus in the clinical cases of pyoderma in the study (Table 1) is in accordance with the report of Berg et al., (1984) who reported an occurrence of $85.37 \%$ of S. intermedius and Raus and Love (1983) who reported $75.68 \%$ of $S$. intermedius and
$17.73 \%$ of $S$. aureus following a study of coagulase positive isolates. However, Medleau et al., (1986) reported the occurrence of S. intermedius in $98 \%$ of the coagulase positive isolates examined and Philips and Williams (1984) reported the presence of $S$. intermedius in $83 \%$ of coagulase positive isolates examined. Woldehiwet and Jones (1990) also confirmed observations of other workers that $S$. intermedius was the dominant coagulase positive species in dogs. However, there are also reports of occurrence of other species of staphylococci such as S. schleiferi (Frank et al., 2003) and S. delphini (Lewis, 2010) in dogs with pyoderma but these are most commonly found in recurrent pyoderma and not as primary pathogens as reported by Frank et al., (2003).

Table.1 Results of Staphylococcal culture of material from lesions of dogs with pyoderma $(n=91)$

\begin{tabular}{|l|c|c|c|c|}
\hline & Coagulase & \multicolumn{3}{|c|}{ Coagulase positive } \\
\cline { 4 - 5 } & negative & Total & S.aureus & S. intermedius \\
\hline Total No. of isolates & 3 & 88 & 16 & 72 \\
\hline Per cent & 3.30 & $\mathbf{9 6 . 7 0}$ & $\mathbf{1 8 . 1 8}$ & $\mathbf{8 1 . 8 1}$ \\
\hline
\end{tabular}

Table.2 Results of antibiotic sensitivity and resistance patterns with Methicillin and Oxacillin in dogs with pyoderma by disc diffusion method

\begin{tabular}{|l|c|c|c|}
\hline \multicolumn{1}{|c|}{ Antibiotic disc } & Sensitive & Resistant & Per cent resistance \\
\hline Methicillin (n=88) & 74 & 14 & 15.91 \\
\hline Oxacillin (n=88) & 74 & 14 & 15.91 \\
\hline
\end{tabular}

Table.3 Comparison of Methicillin resistance of $S$ aureus and $S$ intermedius in dogs with pyoderma

\begin{tabular}{|c|c|c|c|c|c|c|c|}
\hline \multicolumn{4}{|c|}{$\mathbf{S}$} & \multirow{2}{*}{\multicolumn{2}{|c|}{$\begin{array}{c}\text { Comparison with only } S \text {. } \\
\text { aureus isolates } \mathrm{n}=16\end{array}$}} & \multirow{2}{*}{\multicolumn{2}{|c|}{$\begin{array}{l}\text { Comparison with only } S \text {. } \\
\text { intermedius isolates } \mathrm{n}=72\end{array}$}} \\
\hline S aur & & $S$ interm & & & & & \\
\hline $\begin{array}{l}\text { Numbers } \\
\text { resistant }\end{array}$ & $\begin{array}{l}\text { Per } \\
\text { cent }\end{array}$ & $\begin{array}{l}\text { Numbers } \\
\text { resistant }\end{array}$ & $\begin{array}{l}\text { Per } \\
\text { cent }\end{array}$ & $\begin{array}{l}\text { Numbers } \\
\text { resistant }\end{array}$ & Per cent & $\begin{array}{l}\text { Numbers } \\
\text { resistant }\end{array}$ & Per cent \\
\hline 5 & 5.68 & 9 & 10.23 & 5 & 31.25 & 9 & 12.5 \\
\hline
\end{tabular}

* 6 of the 14 Methicillin resistant isolates were subjected to DNA isolation and PCR and 4 were found positive for mecA gene, which is one of the important genes responsible for methicillin resistance 
Fig.1 and 2 Colonies of staphylococcus spp in Mannitol salt Agar isolated from a case of pyoderma in dog. Note the change in colour and the mixed type of growth
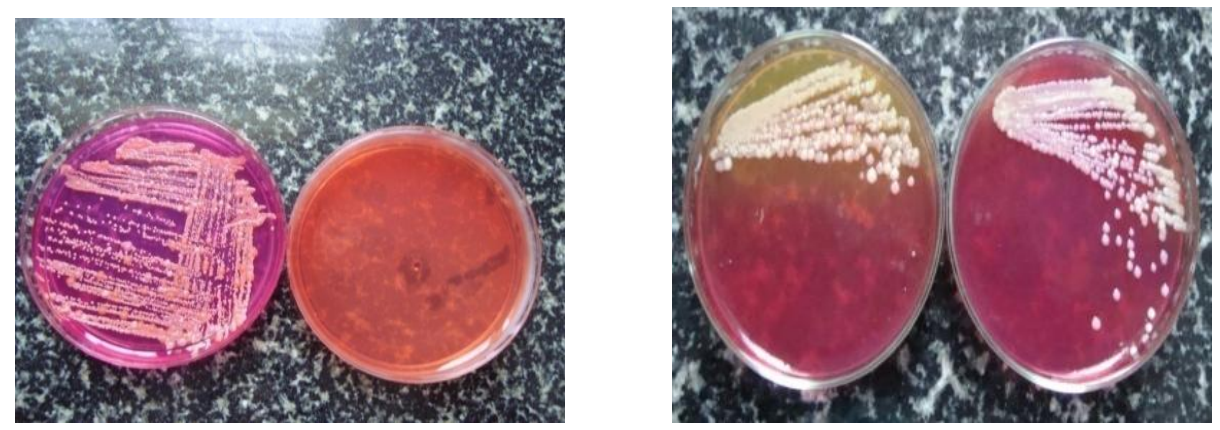

Fig.3 Coagulase Test on isolates from lesions of pyoderma in dogs

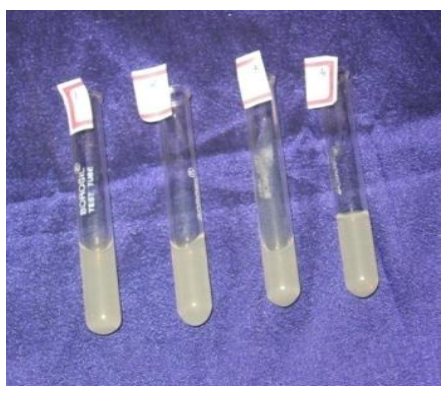

Fig.4 Gram staining of culture of purulent material from skin showing S. intermedius Grams x 1000

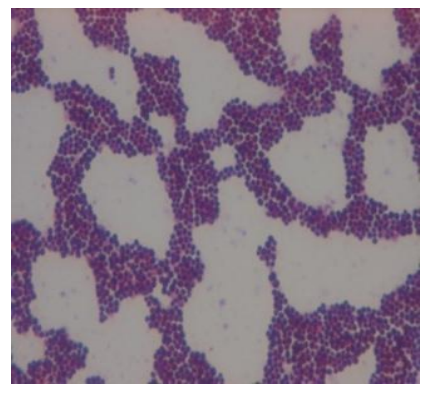

Fig.5 Gram staining of culture of purulent material from skin showing S. intermedius Grams x 1000

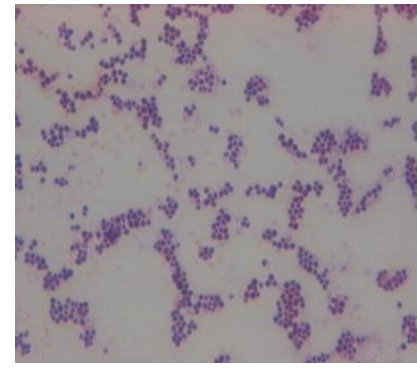


Fig.6 Biochemical tests for identification of staphylococcal species with a commercial kit- Hi staph kit (Himedia)

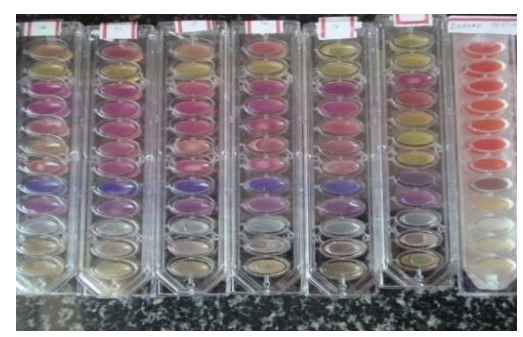

Fig.7 Antibiotic sensitivity test for Methicillin showing zone of inhibition

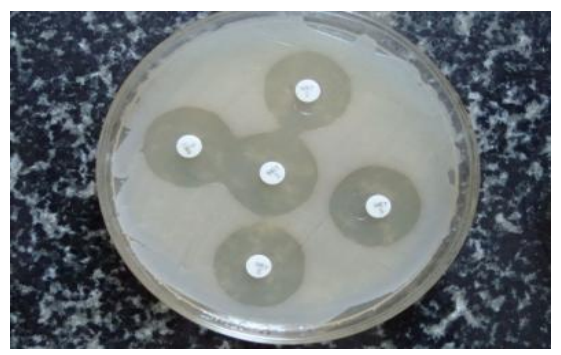

Fig.8 Colony of staphylococcus sp showing resistance to Methicillin

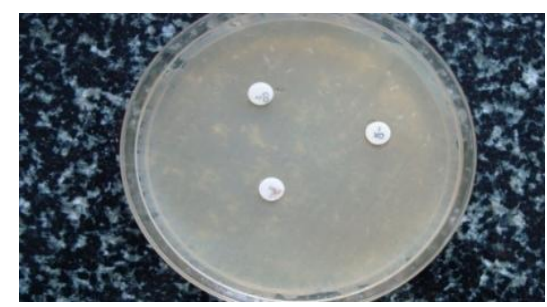

Fig.9 Photograph of PCR with 4 of isolates showing 304 bp corresponding to mecA gene indicating methicillin resistance

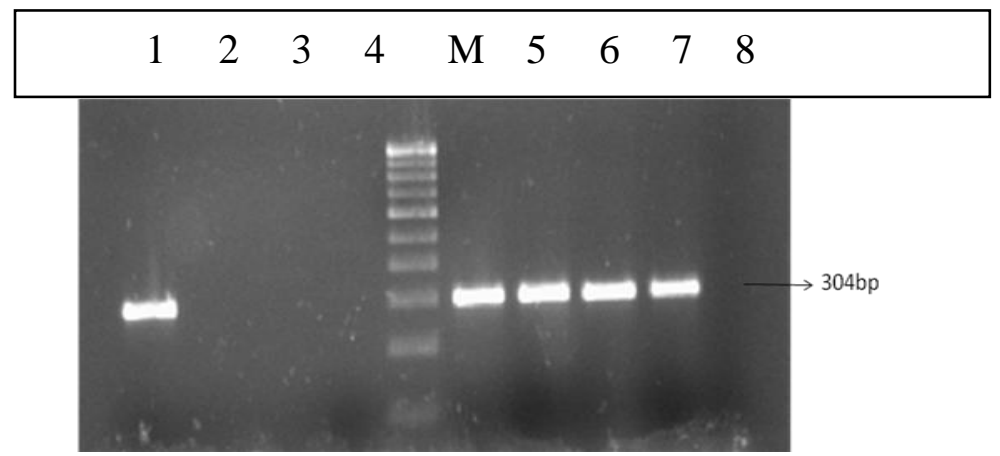

Lane 1: Positive control (phenotypically and genotypically methicillin resistant S.aureus ) Lane 2: Negative control (phenotypically methicillin sensitive S. aureus)

Lane M: $100 \mathrm{bp}$ DNA ladder

Lane 3-8- samples (3, 4-negative: 5 ,6, 7, 8-Positive) 


\section{Detection of methicillin resistance}

The results of Methicillin and Oxacillin sensitivity/resistance testing are depicted in Table 2 and 3 and Fig 7,8 and 9. All the 88 coagulase positive isolates were subjected to sensitivity testing using methicillin and oxacillin discs. A total of 14 isolates i.e. $15.91 \%$ were found to be phenotypically methicillin resistant and the remaining 74 isolates were methicillin sensitive. Of the 14 methicillin resistant isolates, 5 of the isolates $(5.68 \%)$ were $S$. aureus and 9 of the isolates (10.23\%) were S. intermedius.

The results of species-wise methicillin resistance are depicted in Table 2. On species wise assessment of the result of culture examination Methicillin Resistant S. aureus (MRSA) was $31.25 \%$ (i.e. 5 out of 16) and Methicillin Resistant $S$. intermedius (MRSI) was $12.5 \%$ (9 out of 72).

Six of the methicillin resistant staphylococci isolates (four $S$ intermedius and two $S$ aureus as per biochemical characterization) were further subjected to genotyping. Four of the six isolates (Three $S$ intermedius and one $S$ aureus) corresponded to304 bp in the DNA ladder corresponding to $m e c A$ gene specific for methicillin resistance. The results are illustrated in Fig 9.

Methicillin resistant Staphylococci have emerged as serious pathogens over the last decade. These strains are usually multidrug resistant thus making successful therapy difficult. Besides they are now a major cause of hospital and community acquired infections associated with high morbidity and mortality. Further because of the close association between man and animals the threat of transmission of diseases from man to animals and animals to man cannot be overemphasized.
In the present investigation, of the 88 coagulase positive isolates, methicillin resistance (phenotypically) was found in 14 (15.91\%) which included 5 (5.68\%) S. aureus and $9(10.23 \%) S$ intermedius. On a cursory glance it would appear that occurrence of methicillin resistance is more in $S$. intermedius. However when one compares the total number of positive isolates of $S$. intermedius (72) and $S$. aureus (16) to the methicillin resistant isolates i.e. five $S$. aureus and nine $S$. intermedius, it is evident that the incidence of methicillin resistant S.aureus (MRSA) is far more $(31.25 \%)$ than methicillin resistant $S$. intermedius $(12.5 \%)$ The occurrence of methicillin resistant $S$. aureus in humans as well as in animals is being reported since the early 1970s. However, it is the emergence of methicillin resistant $S$. intermedius that is a cause for concern especially because of its zoonotic potential, which is slowly being realized, as a result of the close association between dogs and their owners. Thus it could have far reaching implications not only for pets but for humans as well. A similar report had been made by Bemis et al., (2006) who however reported occurrence of methicillin resistant S.intermedius following a comparative study to be as high as $30 \%$. Similarly, Duquette and Nuttall (2004) reported 23 of the 25 methicillin resistant isolates from canine wounds and skin lesions to be mecA gene positive, of which nine were MRSA, one was MRSI and fifteen were coagulase negative species of staphylococci.

DNA isolation and PCR analysis of six of the isolates showing methicillin resistance by disc diffusion method confirmed four isolates to be positive for mecA gene. Methicillin resistance is due to a modified Penicillin Binding Protein, PBP2a encoded by the mecA gene located on one of the six types of Staphylococcal Chromosomal Casettes (SCCS) which vary in size and the smallest of 
these containing the mecA gene is SCC mec type IV according to Morgan (2008). Loeffler et al., (2007) in fact, first reported the emergence of multidrug resistant and methicillin resistant $S$. intermedius in Europe which was identified by the presence of mecA gene. Gradelski et al., (2001) also reported a positive correlation between methicillin and oxacillin resistance and presence of mecA gene. However they also stated that at least $50 \%$ of the mecA negative strains were falsely classified as methicillin and oxacillin resistant. This may be due to the fact that there are additional genetic materials responsible for methicillin resistance including genes encoding production of Panton Valentine Leucocidin (PVL) which are comparatively less common in animals as reported by Morgan, (2008), Duquette and Nuttall, (2004). Thus the negative results of 2 of the isolates for mecA gene in the present study could be attributed to either overestimation of methicillin resistance by disc diffusion as reported by Duquette and Nuttall (2004) who opined that traditional disc diffusion methods overestimate methicillin resistance or it could be due to some other gene mediating resistance as indicated by Morgan (loc.cit).

However, it should be emphasized that in the present study, $S$ intermedius was identified phenotypically by morphology and biochemical characterization and it is now being reported that the isolates being identified as $S$ intermedius could very well be $S$. psuedintermedius as the two species cannot be differentiated phenotypically by biochemical characterization. However methicillin resistance of these organisms was detected both phenotypically by antibacterial sensitivity testing as well as genotypically by PCR for the presence of mecA gene. Hence the importance of occurrence of Methicillin Resistant Staphylococci be it $S$ aureus, $S$. intermedius or $S$. pseudintermedius cannot be overemphasised considering the zoonotic threat these organisms represent and also the difficulty in treating such infections.

\section{Acknowledgements}

The authors would like to gratefully acknowledge the Vice Chancellor, KVAFSU, Bidar and The Dean, Veterinary College Bangalore, Karnataka, for providing the facilities to undertake this study.

\section{References}

Bauer, A.W., Kirby, W.M.M., Sherris., J.C. and Truck, M., 1966. Antibiotic susceptibility testing by a standardised single disc method. Am J Clin Pathol. 36: 493-496

Bemis, D.A, Jones, R.D., Hiatt, L.E., OforI, E.D., Rohrbach B.W., Frank, L.A. and Kania, S.A. 2006. Comparison of tests to detect oxacillin resistance in Staphylococcus intermedius, Staphylococcus schleiferi and Staphylococcus aureus isolates from canine hosts. J Clin Microbiol. 44 (9): 3374 - 3376.

Berg, J.N, Wendell, D.E., Vogelweid, C., Fales, W.H. 1984. Identification of the major coagulase positive staphylococcus Sp of dogs as Staphylococcus intermedius. Am J Vet Res. 45 (7): 1307 -1309.

Craig, M. 2003. Diagnosis and management of pyoderma in the dog. In Practice.7: 418-425

Cruickshank, R., Duguid, J.P., Marmion, B.P. and Swain, R.H.A. 1975. Medical Microbiology. XII Edn Vol II, Churchill and Livingston, New York: PP: 170188.

Deboer, D.J. 1995 Management of chronic and recurrent pyoderma in the dog. In: Kirks Current Veterinary TherapySmall Animal Practice: Ed XII. WB 
Saunders and Co, Philadelphia: PP:611618.

Devriese, L.A., Vancanneyt, M., Baele. M., Vaneechowtte M., De Graef, E., Snauwaert. C., Cleenwerck, I., Dannydt, P., Swings, J., Decostere, A and Haesebrouk, F. 2005. Staphylococcus pseudintermedius sp. Nov., a coagulase positive species from animals. Int J Sysy Evol Microb (IJSEM): 55 (4): 15691573.

Duquette, R.A and Nuttall, I. J. 2004. MRSA in cats and dogs- An Emerging Problem?: J Small Anim Pract. 45: 591 $-597$

Elmer, WW; Allen, S.D., Dowell Jr, Janda, W.M., Sommers, H.M. and Win, W. C., Jr., 1988. Color Altas and Text book of Diagnostic Microbiology. III Edn., J.B. Lippincott Co., Philadelphia. PP 96-98

Fitzgerald, J.P.2009. The Staphylococcus intermedius group of bacterial pathogens: Species re-classification, pathogenesis and the emergence of methicillin resistance. Vet Dermatol. 20 (5-6): 490-495.

Frank, L.A., Kania, S.A, Hnilica, K.A, Wilkes, R.P and Bemis, D.A. 2003. Isolation of Staphylococcus schleiferi from dogs with pyoderma. $J$ Am Veterinary Med Assoc. 222 (4): 451455.

Frank, L.A. and Loeffler, A. 2012. Methicillin resistant

Staphylococcus pseudintermedius: Clinical challenge and treatment options. Vet Dermatol. 23 (4):283-e56

Gradelski, E., Valera, L., Aleksuxes, L., Bonner, D and Fung Tomc, J. 2001. Correlation between genotype and phenotypic categorization of staphylococci based on methicillin susceptibility and resistance. $J$ Clin Microbiol. 39 (8): 2961-2963.

Hoskin, D.J., Newman, S.S., Roy, A.F., Foil, C.S. and Hollis Utah Cox. 1985.
Detection of B. lactamase produced by Staphylococcus intermedius. American. $J$ Vet Res. 46: 1526-1528.

Ihrke, P.J. 1983. The management of canine pyodermas. In: Current Veterinary Therapy. VII Edn; R.W. Kirk. Pub: WB Saunders Co., Philadelphia. PP: 505517

Kunkle, G.A., 1987. Clinical Management of canine pyoderma. Proc 11th Annual Kal Kan Symposium for the Treatment of Small Animal Diseases. PP: 55-61.

Lewis, D.T., 2010. Dermatologic Disorders. In: Clinical Medicine of the Dog and Cat. IInd Edition: Editor Michael Schaer: Manson Publishing Ltd. PP: 949.

Loeffler, A, Linek, M., Moodley, A., Guardabassi, L., Sung, J.M., Winkler, M., Weiss R and Lloyd, D.H. 2007. First report of multiresistant mecA positive Staphylococcus intermedius in Europe: 12 cases from a veterinary referrel clinic in Germany. Vet Dermatol: 18 (6): 412-421.

Mason, I.S. 1997. Canine superficial pyoderma. Waltham focus. 7: 9-15

Medleau, L., Long, R.E., Brown, J and Miller, W.H. 1986. Frequency and antimicrobial susceptibility of Staphylococcus species isolated from canine pyodermas. Am J Vet Res. 47 (2): $229-231$.

Morgan, M. 2008. Methicillin resistant Staphylococcus aureus and animals: zoonosis or humanosis? J Antimicrob Chemoth. 62 (6): 1181-1187.

Philips, W.E.(Jr) and Williams, B.J., 1984. Antimicrobial susceptibility patterns of canine Staphylococcus intermedius isolates from veterinary clinical specimen. Am J Vet Res. 45 (II): 23762379.

Raus, J. and Love D.N 1983. Characterization of coagulase positive Staphylococcus intermedius and Staphylococcus aureus 
isolated from veterinary clinical specimen. J Clin Microbiol. 18 (4): 789792.

Sundareshan, S. 2012. Studies on phenotypic and molecular characterization of coagulase negative staphylococci isolated from clinical and subclinical cases of bovine mastitis. Ph.D thesis. Karnataka Veterinary, Animal and Fisheries Sciences University, Bangalore, India.
Woldehiwet, Z and Jones, J.J. 1990. Species distribution of coagulase positive staphylococci isolated from dogs. Veterinary Record., 126 (19):485.

Zakour, N.L.B., Beatson, S.A., Van Den Broek, A.H.M., Thoday, K.L. and Fitzerald, J.R. 2012. Comparative genomics of the Staphylococcus intermedius group of animal pathogens. Front Cell Infect Microbiol. 2: 44.

\section{How to cite this article:}

Kshama, M. A., S. Yathiraj, Srikrishna Isloor, S. Sundaresh and Veeresh, B. H. 2020. Identification of Methicillin Resistant Staphylococcus intermedius and Staphylococcus aureus in Dogs with Pyoderma. Int.J.Curr.Microbiol.App.Sci. 9(09): 2122-2131. doi: https://doi.org/10.20546/ijcmas.2020.909.265 